\title{
Influence of Manufacturing Parameters on Performance of Biodegradable Mg-Ca1.0 Implant
}

\author{
S. Desai ${ }^{1}$, R. Pawade ${ }^{2}$, H. Warhatkar ${ }^{3}$ \\ ${ }^{1}$ Assistant Professor, Dr. D.Y Patil Engineering College Akurdi, SPPU, Pune India \\ ${ }^{2}$ Associate Professor, ${ }^{3}$ Associate Professor, Dr. Babasaheb Ambedkar Technological University, Lonere, Raigad, India \\ \{sandeepdesai022@gmail.com\}
}

\begin{abstract}
The paper reports the effects of machining parameters on performance of biodegradable magnesium calcium alloy implant in terms of surface roughness, microstructure, microhardness, chip morphology and degradation rate in face milling using CVD diamond like carbon coated carbide inserts. The result shows that the corrosion resistance of forged sample is higher than that of cast sample. It is also found that the surface roughness is the most significant factors affecting degradation rate. Degradation is mainly occured due to pitting corrosion phenomena. A fine grain microstructure is observed in forged sample and $\mathrm{Mg}_{2} \mathrm{Ca}$ phase is uniformly distributed in microstructure which improves the corrosion resistance. During machining microhardness is changed from $66 \mathrm{Hv}$ to $84 \mathrm{Hv}$ due to effect of machining parameters. As far as the chip morphology is concerned the depth of cut has significant influence on helical distance of chip.
\end{abstract}

Keywords: Surface integrity, Magnesium-calcium alloy, Degradation, Microstructure, Face milling

\section{Introduction}

Biodegradable implants which dissolve in the human organism will be an ideal solution to the challenges of "stress shielding" and "surgical interventions" caused by metallic implants [1]. Nowdays, Mg-based alloys have received a lot of attention due to their properties nearly equal to that of bone. Magnesium and magnesium alloys are nonferrous metals with low density, good ductility, moderate strength and good corrosion resistance. It has been found from the vivo studies that the magnesium-calcium alloys are suitable as degradable biomaterial for use in medical implant [2-6]. In degradation process of $\mathrm{MgCa} 1.0$ alloy, main corrosion products are calcium and phosphorus. Calcium is the main constituent of bone and phosphate provides that structural rigidity to bone.

Raman [5] examined the degradation behaviour of $\mathrm{MgCa}$ alloy. They found significant improvement in that pitting corrosion resistance of calcium-containing magnesium alloys was significantly improved. Koleini et al. [7] studied the influence of hot rolling parameters on microstructure and biodegradability of MgCa1.0 alloy. They expressed that more thickness reduction caused less corrosion and high preheated temperature of the $\mathrm{MgCa}$ implant increases the corrosion. Harandi et al. [8] observed that after forging, mechanical strength and corrosion resistance of MgCa1 alloy was improved. Denkena et al. [9] observed that the lower cutting speed gives lower corrosion rate in turned $\mathrm{Mg}-\mathrm{Ca} 3.0$ alloy. Hoh et al. [10] examined the degradation behavior of $\mathrm{MgCa} 0.8$ produced by turning, sand-blasting, and threading operations. It is noted that increase in surface roughness led to a faster degradation rate. Salahshoor [11] studied dry high-speed face milling of $\mathrm{MgCa} 0.8$ alloy using PCD tipped tool and found that the cutting parameters lead to changes in the microstructure in near surface due to thermal effects. The compressive residual stresses induced in the implant slows down the corrosion rate of the implant in human body fluid. It is found that an increase in cutting speed and feed rates, causes the increase in microhardness. Friemuth et al. [13] carried out turning and subsequent rolling of AZ91 magnesium alloy and noted that increase in surface hardness and induced compressive stresses in the subsurface further increase the corrosion resistance. Birol [14] found that the higher cutting speed causes inhomogeneous shear strain and the chip changes from continuous chip to saw-tooth chip.

Based on the extensive literature survey, it is noted that few studies reported on the machining performance of $\mathrm{MgCa} 0.8$ alloy. However, no work has been reported on machining of Mg-Ca1.0 forged component using CVDDLC coated carbide inserts which is more improved. Thus the focus of the present study is to determine the effect of machining parameters on implant properties and performance in terms of surface roughness, microhardness, chip morphology and degradation rate.

B. Iyer, S. Nalbalwar and R. Pawade (Eds.)

ICCASP/ICMMD-2016. Advances in Intelligent Systems Research.

Vol. 137, Pp. 252-258.

(C) 2017. The authors - Published by Atlantis Press

This is an open access article under the CC BY-NC license (http://creativecommons.org/licens)es/by-nc/4.0/).

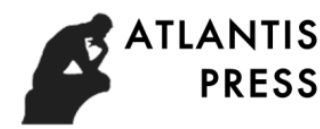




\section{Experimental work}

In present experimental investigation, one factor at a time approach (OFAT) was used. Nineteen experiments were conducted for three factors. Levels selected for cutting speed, depth of cut and feedrate are 7, 5 and 5 respectively. Workpiece material selected is a pressure die cast $\mathrm{MgCa} 1.0$ alloy plates which is forged to improve the strength and corrosion resistance.
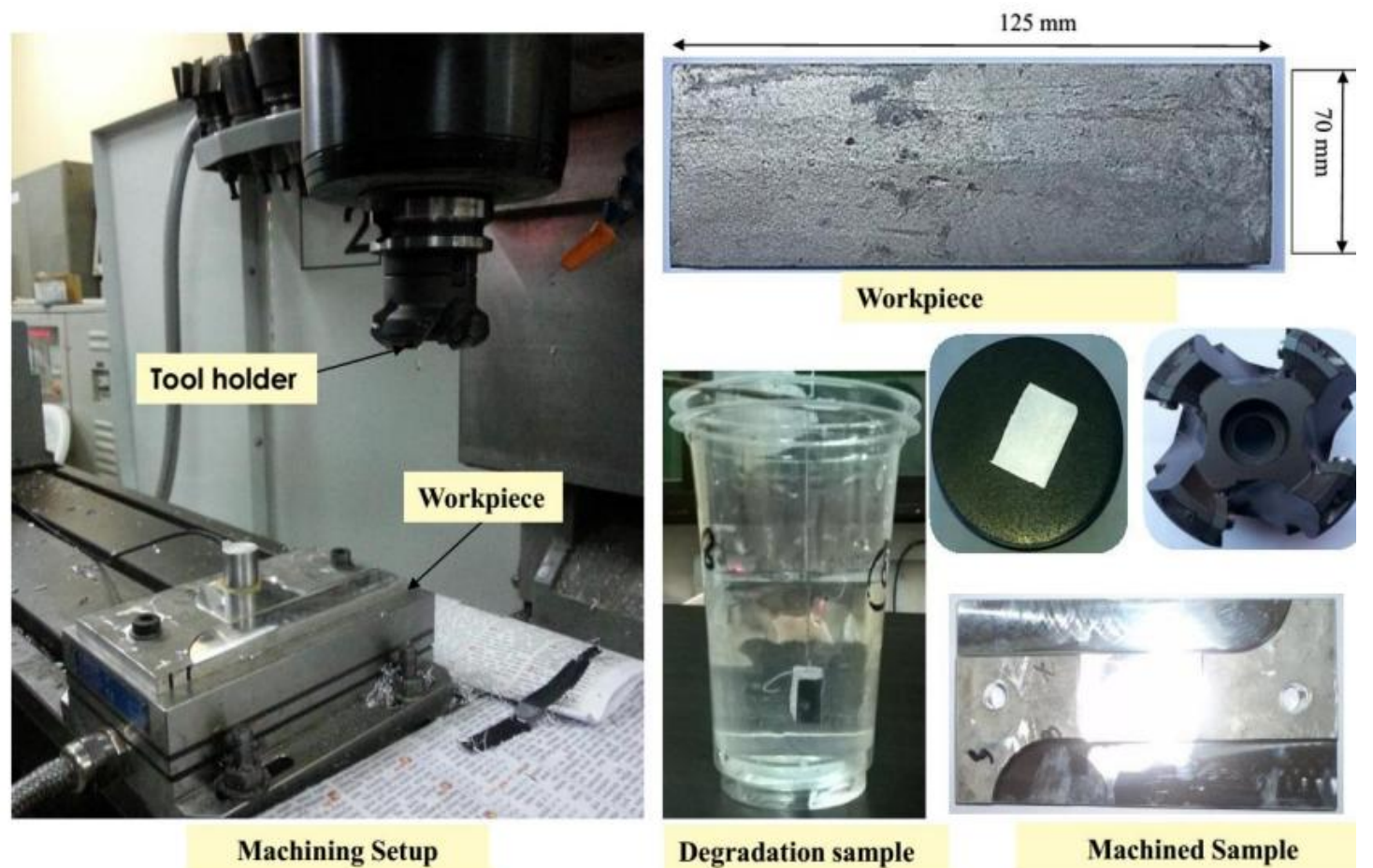

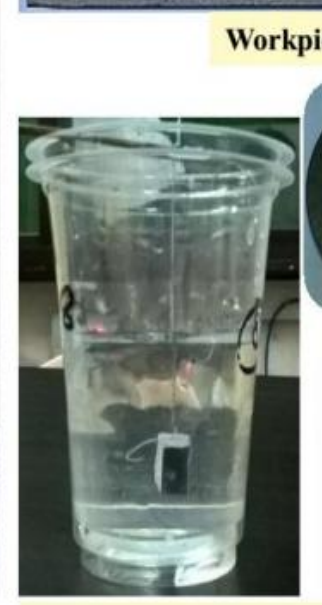

Degradation sample

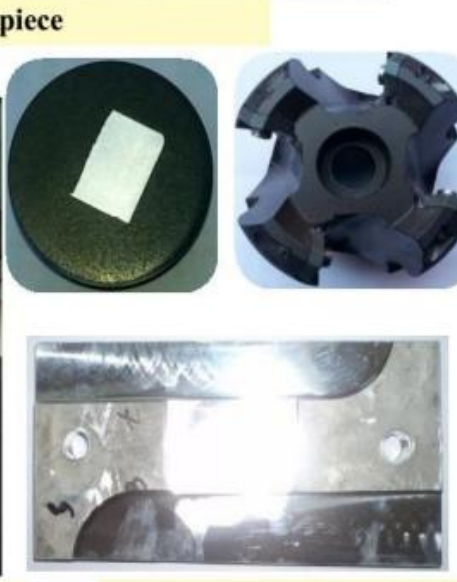

Machined Sample

Fig. 1. Experimental setup

The rectangular plate workpiece of MgCa1.0 magnesium alloy having size $125 \times 70 \times 9 \mathrm{~mm}$ was machined using DLC coated carbide cutting inserts (Make- HITACHI). For every experiment same insert was used and chips were collected. The surface roughness was measured by Mitutoyo surface roughness tester (model- SJ301, make- Mitutoyo). The chip morphology and tool wear was measured using Nikon measuring microscope. Macrostructure of the cast, forged and machined samples was examined by Nikon optical microscope. The microstructure of the samples was characterized using scanning electron microscope. A Vickers microhardness tester was used to measure hardness value of the prepared samples. The sample preparation was carried out by fine grinding using polishing papers up to 2000 grit for weight loss test. The prepared specimens $(18.5 \times 14.5 \times 7$ $\mathrm{mm}$ ) were exposed to hyaluronic acid for a particular time period of 384 hours. In order to monitor the corrosion behavior of the immersed specimens, the weight loss was measured throughout the immersion test after every 24 hours. intervals. After 24 hours interval, the component was removed from test medium and cleaned using distilled water and then dried and weighed and images of the degraded surface were captured. Thereafter, the specimens were reimmersed in the solution.

\section{Results and Discussion}

\subsection{Analysis of surface roughness}

As the cutting speed increases from 300 to $600 \mathrm{~m} / \mathrm{min}$, the machined surface produced is smooth with a roughness value of $0.091 \mu \mathrm{m}$ (Fig. 2a). As the feedrate increases from $0.05 \mathrm{~mm} / \mathrm{rev}$ to $0.5 \mathrm{~mm} / \mathrm{rev}$, the surface roughness $\mathrm{Ra}$ increases from $0.078 \mu \mathrm{m}$ to $0.158 \mu \mathrm{m}$. As the depth of cut increases the increase in surface roughness $R_{\mathrm{a}}$ from $0.107 \mu \mathrm{m}$ to $0.137 \mu \mathrm{m}$ was noted. High speed dry face milling of MgCa1.0 alloy with CVDDLC coated tool produces smooth surface with average $R_{\mathrm{a}}$ value of $0.1 \mu \mathrm{m}$. In most of the experiments the effect of machining parameters on tool wear is found negligible. The maximum crater wear observed after machining nineteen components is found as $148 \mu \mathrm{m}$. 


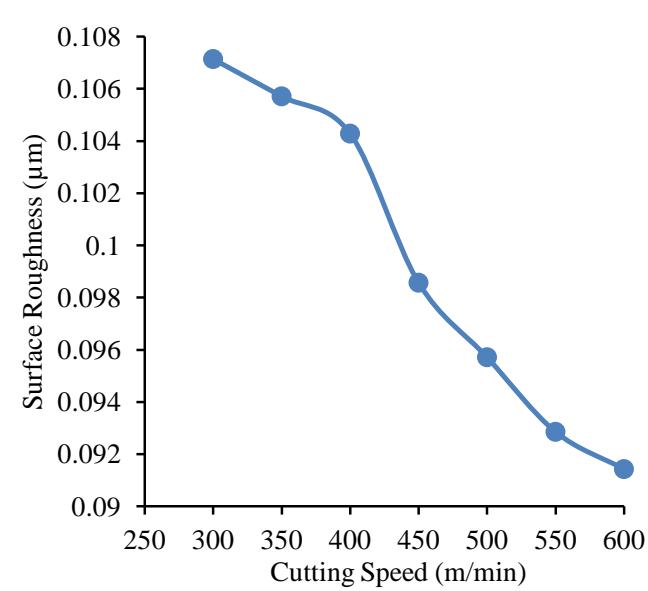

(a)

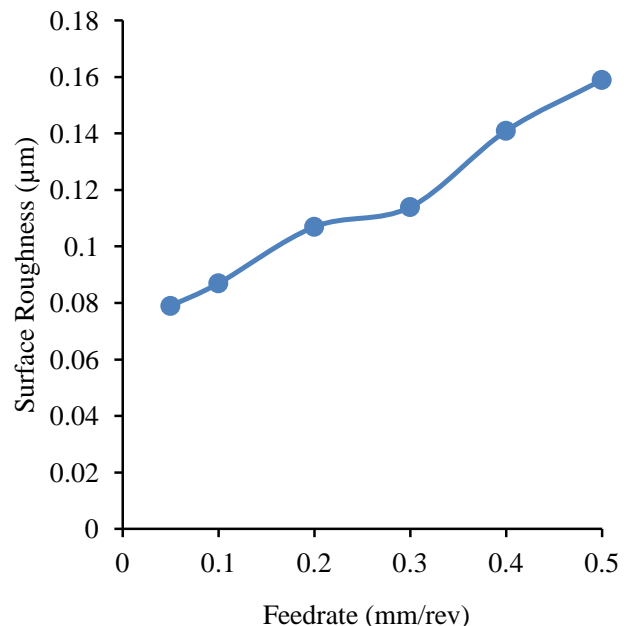

(b)

Fig. 2. Effect of (a) cutting speed, (b) feedrate on surface roughness $R_{\mathrm{a}}$

\subsection{Analysis of microhardness}

Cast $\mathrm{MgCa} 1.0$ alloy is having microhardness of $45 \mathrm{Hv}$, while in the case of forging process grain refinement of microstructure was occurred and hardness increased up to 63HV. Further during machining increase in microhardness up to $84 \mathrm{Hv}$ was reported due to grain refinement because of thermo-mechanical loading during machining [1]. It is noticed that with an increase in the cutting speed from $300 \mathrm{~m} / \mathrm{min}$ to $350 \mathrm{~m} / \mathrm{min}$, the microhardness reduces from $85.3 \mathrm{Hv}$ to $73.6 \mathrm{Hv}$ (see Fig. 3a). This can be attributed to larger compressive residual stresses generated due to large cutting forces at lower cutting speeds. Further increment in the cutting speed from $400 \mathrm{~m} / \mathrm{min}$ to $600 \mathrm{~m} / \mathrm{min}$, a corresponding increase in the microhardness is noted due to strain hardening. It is noted that as the feedrate increases the microhardness of the surface reduces gradually (see Fig.3b).
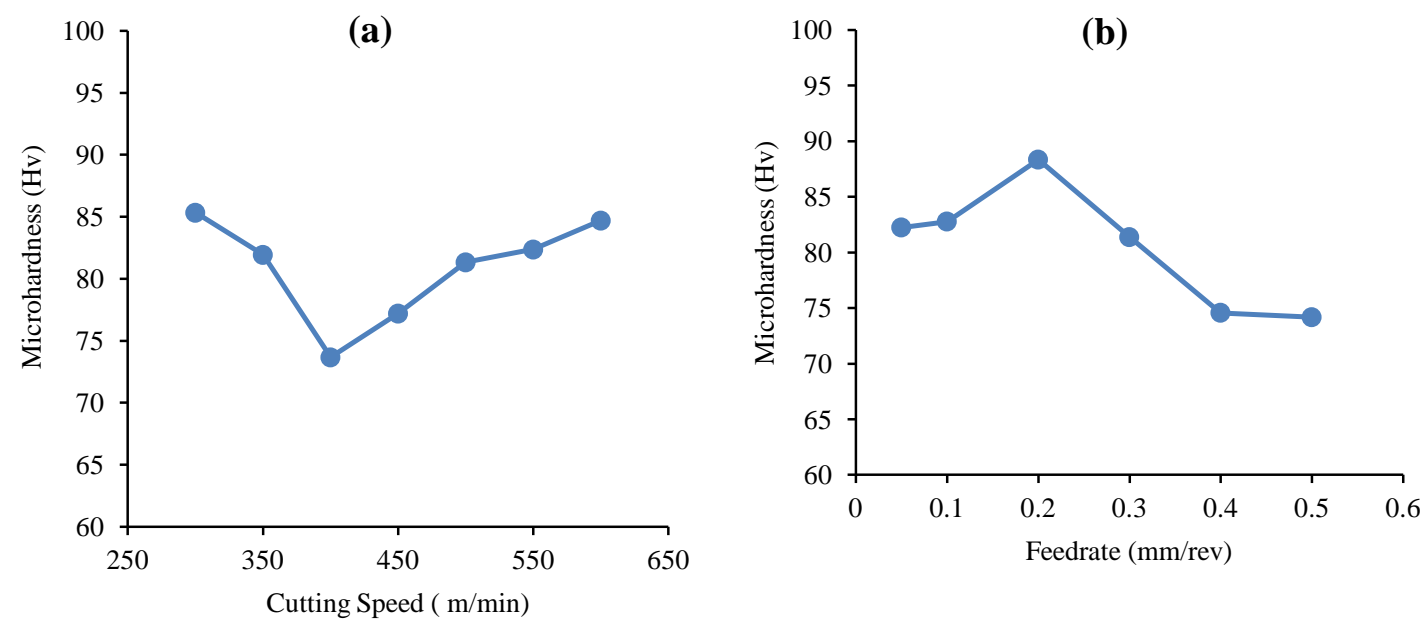

Fig. 3. Effect of cutting speed and feedrate on microhardness 
Table 1 The measured surface roughness, microhardness and helical distance during one factor at a time approach

\begin{tabular}{|c|c|c|c|c|c|c|}
\hline \multirow{2}{*}{$\begin{array}{l}\text { Exp. } \\
\text { No. }\end{array}$} & \multicolumn{3}{|c|}{ Process Parameters } & \multirow{2}{*}{$\begin{array}{l}\text { Avg. Surface } \\
\text { Roughness } R_{\mathrm{a}} \\
(\mu \mathrm{m})\end{array}$} & \multirow{2}{*}{$\begin{array}{c}\text { Avg. } \\
\text { Microhardness } \\
\text { (HV) }\end{array}$} & \multirow{2}{*}{$\begin{array}{c}\text { Avg. } \\
\text { Helical } \\
\text { Distance } \\
(\mu \mathrm{m}) \\
\end{array}$} \\
\hline & $\begin{array}{l}\text { Cutting Speed } \\
\qquad(\mathrm{m} / \mathrm{min})\end{array}$ & $\begin{array}{l}\text { Feedrate } \\
(\mathrm{mm} / \mathrm{rev})\end{array}$ & $\begin{array}{l}\text { Depth of } \\
\text { Cut }(\mathrm{mm})\end{array}$ & & & \\
\hline 1 & 300 & 0.3 & 0.2 & 0.107 & 85.33 & 166.5 \\
\hline 2 & 350 & 0.3 & 0.2 & 0.106 & 81.93 & 187 \\
\hline 3 & 400 & 0.3 & 0.2 & 0.107 & 73.67 & 196.75 \\
\hline 4 & 450 & 0.3 & 0.2 & 0.099 & 77.2 & 238.75 \\
\hline 5 & 500 & 0.3 & 0.2 & 0.096 & 81.33 & 284 \\
\hline 6 & 550 & 0.3 & 0.2 & 0.093 & 82.36 & 311.75 \\
\hline 7 & 600 & 0.3 & 0.2 & 0.091 & 84.7 & 340.25 \\
\hline 8 & 450 & 0.05 & 0.2 & 0.079 & 82.23 & 291.75 \\
\hline 9 & 450 & 0.1 & 0.2 & 0.087 & 82.76 & 303.5 \\
\hline 10 & 450 & 0.2 & 0.2 & 0.107 & 88.33 & 397.75 \\
\hline 11 & 450 & 0.3 & 0.2 & 0.114 & 81.36 & 447 \\
\hline 12 & 450 & 0.4 & 0.2 & 0.141 & 74.56 & 551 \\
\hline 13 & 450 & 0.5 & 0.2 & 0.159 & 74.16 & 543.5 \\
\hline 14 & 450 & 0.3 & 0.05 & 0.107 & 74.23 & 269.5 \\
\hline 15 & 450 & 0.3 & 0.1 & 0.116 & 73.2 & 226.5 \\
\hline 16 & 450 & 0.3 & 0.2 & 0.113 & 73.73 & 320.25 \\
\hline 17 & 450 & 0.3 & 0.3 & 0.116 & 71.3 & 220.25 \\
\hline 18 & 450 & 0.3 & 0.4 & 0.137 & 75.7 & 174.75 \\
\hline 19 & 450 & 0.3 & 0.5 & 0.127 & 77.9 & 169.5 \\
\hline
\end{tabular}

\subsection{Analysis of chip morphology and chip behaviour}

In face milling of MgCa1.0 magnesium alloy the chip morphology under different cutting conditions revealed generation of five types of chips as powdered chips, tubular helical chips, acicular helical chip, long belt chip and spiral chip (see Fig. 5). Chip behaviour is effect on surface finish and tool life therefore it indirectly effect on degradation rate.

The parameters that indicate the helix nature of chip is defined here as "Helical distance" to understand better the chip morphology produced in face milling. It is observed from the graph (Fig. 6a) that, with an increase in cutting speed from $300 \mathrm{~m} / \mathrm{min}$ to $600 \mathrm{~m} / \mathrm{min}$, the helical distance of chip increases up to $340.25 \mu \mathrm{m}$. The reason behind the increase in helical distance might be at higher cutting speed, the chips sliding from the rake surface with smaller radius of curvature and hence minimum bend radius. A similar effect is found in the case of feed rate. 

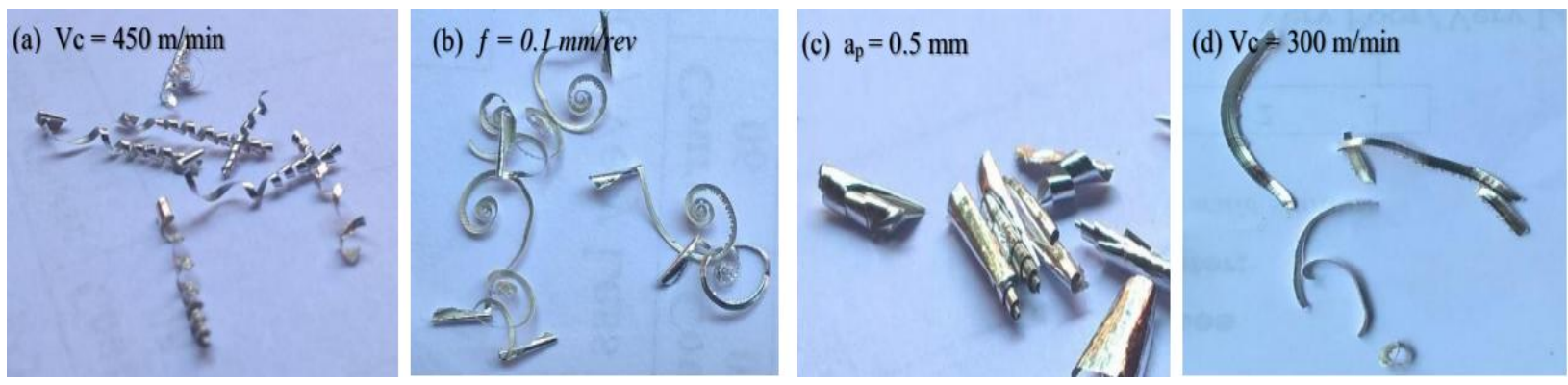

Fig. 5. Types of chips (a) tubular helical chips, (b) spiral shape chip, (c) long belt chip and (d) acicular helical chip

It is seen that as the depth of cut increases the helical distance of chip decreases from $269.5 \mu \mathrm{m}$ to $169.5 \mu \mathrm{m}$. This can be attributed to the fact that at higher depth of cut, increase in cutting force results increase in the chip deformation and decrease in chip flow angle. These in turn causes decrease in helical distance [15]. At $0.2 \mathrm{~mm}$ depth of cut helical distance of the chip increases, this might happen because of change in chip behaviour from spiral shape chip to helical tubular chip.

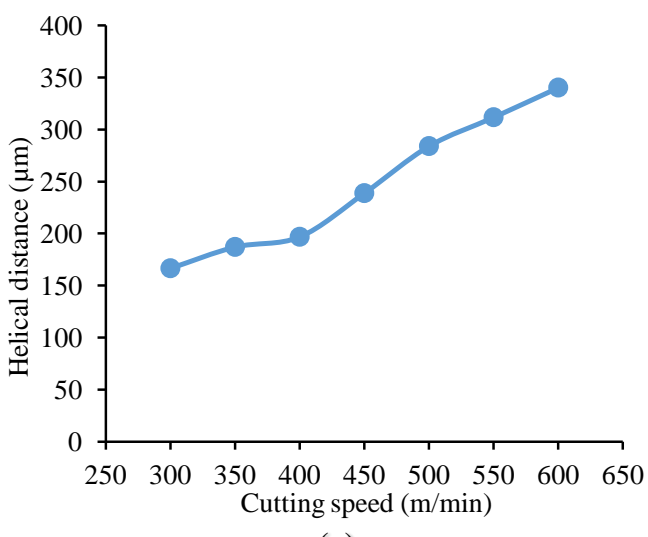

(a)

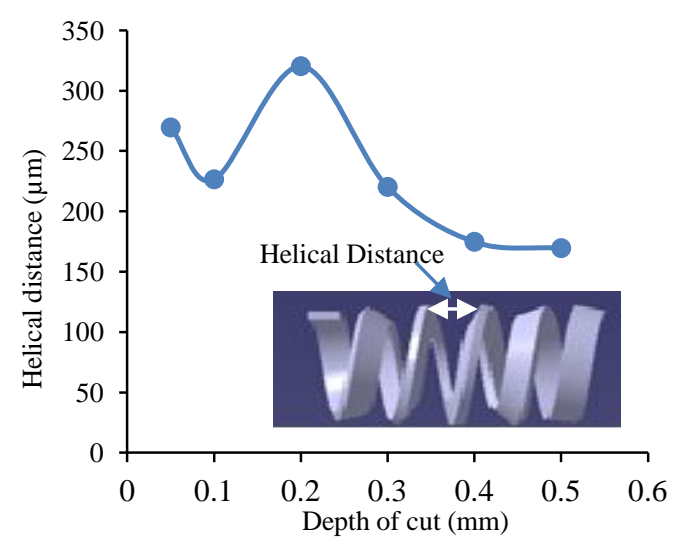

(b)

Fig. 6. Effect of (a) cutting speed, and (b) depth of cut on helical distance of chip

\section{A. Analysis of degradation rate}

Degradation rate is the most significant parameters in bio-implant service life. Fig.7 shows the weight loss of cast, forged and machined sample in body solution. It is seen that as-cast sample showed more weight loss than the forged sample. A prominent pitting corrosion was noticed during degradation experiment of magnesium alloy. Fig.8 shows surface images of cast, forged and machined sample after 96 hours immersion of sample. Pitting corrosion occurs when distinct areas of material undergo rapid attack while the other majority of the surface remains unaffected. As the microstructure in $\mathrm{Mg}$-Ca alloys usually contains $\alpha$-matrix and $\mathrm{Mg}_{2} \mathrm{Ca}$ phase and $\mathrm{Mg}_{2} \mathrm{Ca}$ phase is more chemically active which is more proven to pitting. It is observed from Fig. 8 that more pitting occured in the cast as compared to forged and machined component.

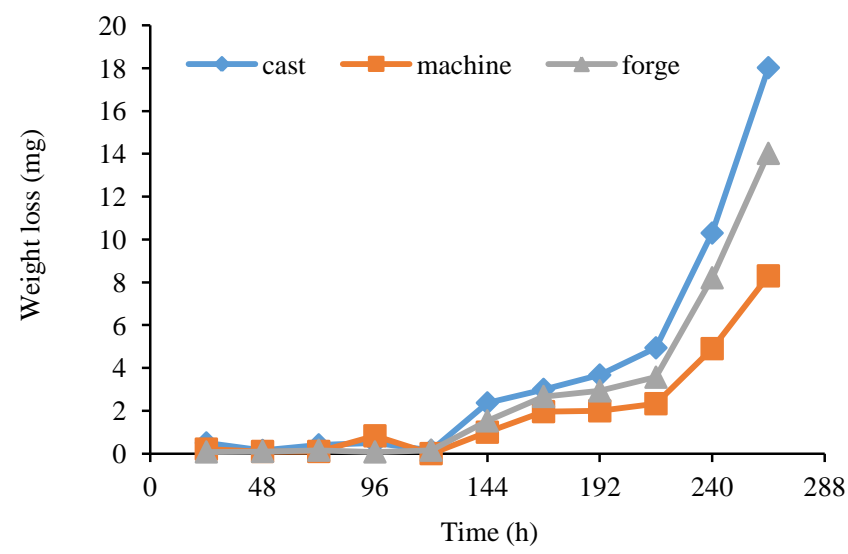

Fig. 7. Effect of casting, forging and machining process on weight loss of the sample 

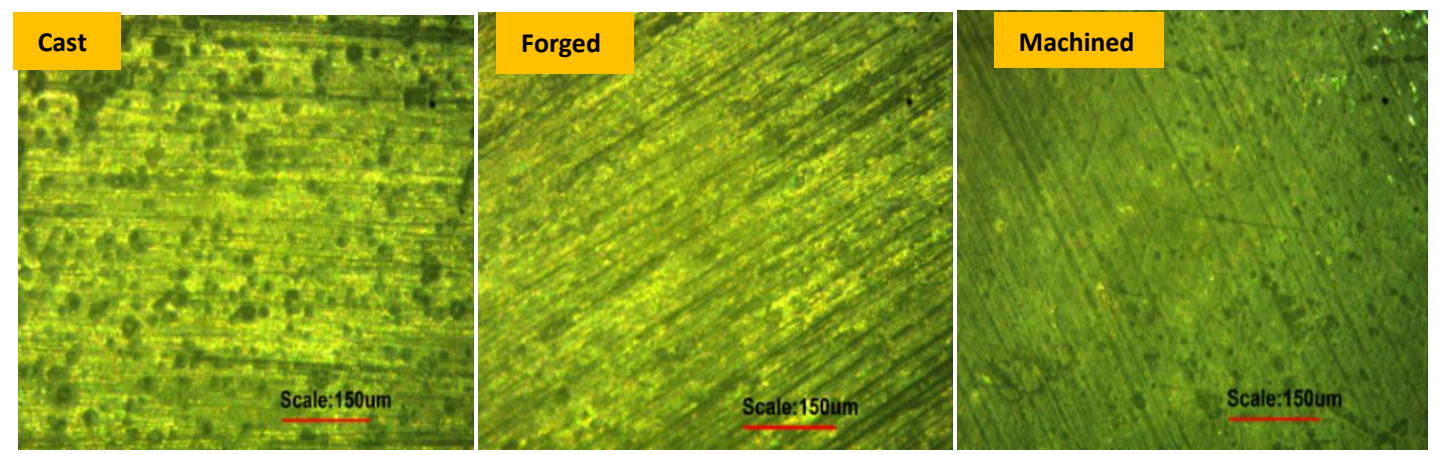

Fig. 8. Microscopic images of cast, forged and machined sample after $96 \mathrm{~h}$

Fig. 9a shows the effect of cutting speed on weight loss. It is found that with an increase in cutting speed, the degradation rate decreases, this could be due to better surface finish and refined and homogeneous microstructure produced at higher cutting speed during machining. Fig. 9b shows the effect of feedrate on weight loss of the machined implant. It is seen that with an increase in the feedrate, weight loss increases because the higher feedrate resulted into lower surface finish. However at $0.05 \mathrm{~mm} / \mathrm{rev}$ feedrate, the lowest weight loss is noticed. Fig. 9c shows that with an increase in the depth of cut, weight loss increases since at higher depth of cut lower surface finish is produced. After 192 hours it is noted that with an increase in depth of cut the weight loss reduces, due to larger cutting forces which resulted in to more compressive residual stresses in the subsurface of material $[8,16]$.

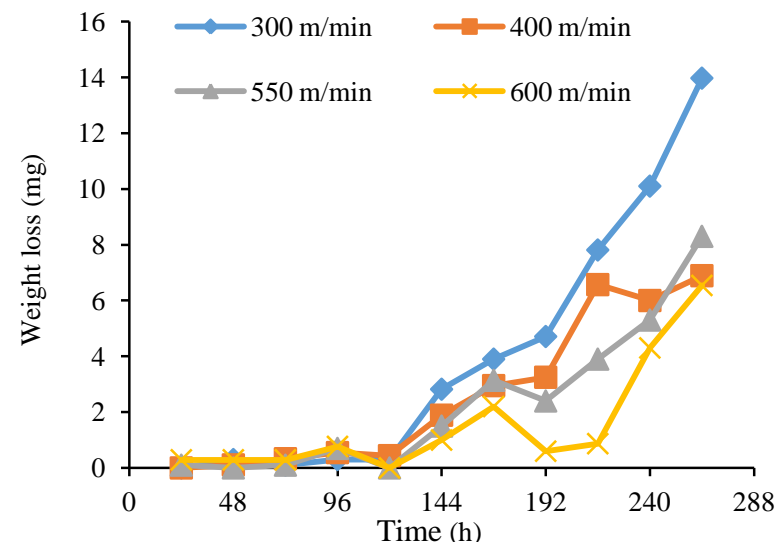

(a)

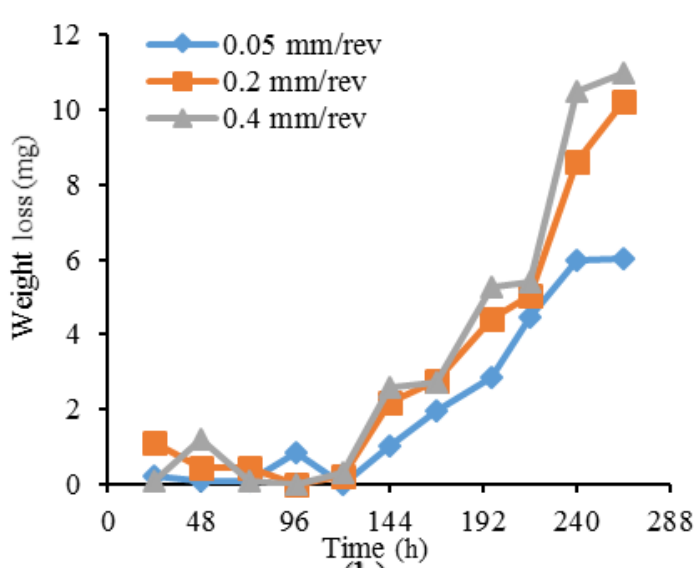

(b)

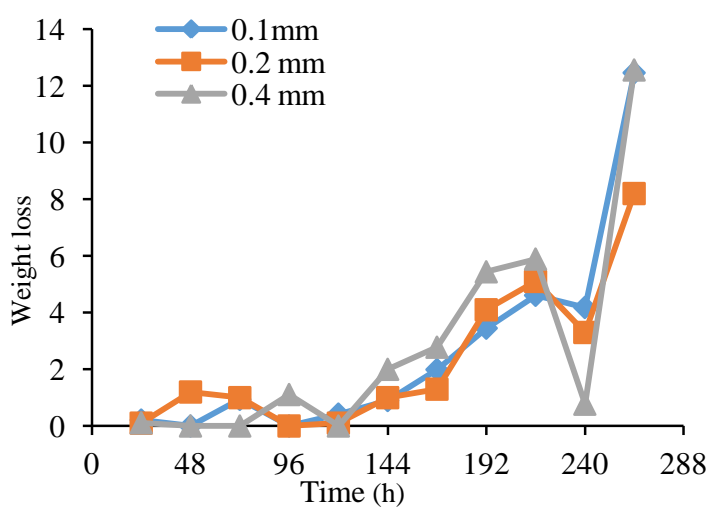

(c)

Fig. 9. Effect of cutting speed, (b) feedrate, and (c) depth of cut on weight loss of the sample 


\section{Conclusions}

1. The feedrate and cutting speed both shows statistically significant effect on the surface roughness $\left(R_{\mathrm{a}}\right)$. The average surface roughness archived is $0.1 \mu \mathrm{m}$.

2. In forging process due to grain refinement the increase in microhardness of cast component up to $63 \mathrm{HV}$ also improve the corrosion resistance and strength of magnesium alloy.

3. Immersion test shows that corrosion resistance of forged component is improved than the cast component. Degradation is mainly occur due to pitting corrosion.

4. Surface roughness significantly affect the degradation behaviour of the machined sample. The machined sample with higher surface finish shows more uniform pitting corrosion.

5. During machining five types of chips are observed powdered chips, tubular helical chips, acicular helical chip, long belt chip and spiral chip. Depth of cut shows more significant on the chip behaviour.

\section{References}

[1]. Meisam Salahshoor and Yuebin Guo, "Biodegradable Orthopedic Magnesium-Calcium (MgCa) Alloys", Processing, and Corrosion Performance, Materials, 2012, 5,135-155.

[2]. Mark P. Staigera and Alexis M. Pietak a et al., "Magnesium and its alloys as orthopedic biomaterials: A review”, 2006, Biomaterials, 27, 1728-1734.

[3]. Gérrard Eddy Jai Poinern et.al, "Biomedical Magnesium Alloys: A Review of Material Properties, Surface Modifications and Potential as a Biodegradable Orthopaedic Implant”, American Journal of Biomedical Engineering 2012, 2(6): 218-240.

[4]. Thomann M. et al., "Comparison of the resorbable magnesium alloys LAE442 and $\mathrm{MgCa} 0.8$ concerning their mechanical properties, their progress". Materialwiss. Werkst., 2009, 40, 82-87.

[5]. Kannan M. B. and Raman, "In vitro degradation and mechanical integrity of calcium containing magnesium alloys in modified simulated body fluid", Biomaterials, 2008, 29, 2306-2314

[6]. Kirkland, N. rT. et al., "A survey of bio-corrosion rates of magnesium alloys", Corrosion Science, 2010, 52, 287-291.

[7]. Shahriar Koleini et al., "Influence of hot rolling parameters on microstructure and biodegradability of Mg-1Ca alloy in simulated body fluid", Materials and Design, 2012, 33, 20-25.

[8]. Shervin Eslami Harandi et al., "Effect of forging process on microstructure, mechanical and corrosion properties of biodegradable Mg-1Ca alloy", Materials and Design, 2011, 32, 2596-2603.

[9]. Denkena et al., "Biocompatible magnesium alloys as absorbable implant materials adjusted surface and subsurface properties by machining processes", Annals of the CIRP, 2007, 56, 113-116.

[10]. Von der Hoh et al.,"Influence of different machining treatments of magnesium-based resorbable implants on the degradation behavior in rabbits" Advances in Engineering Materials, 2009, 11, B47B54.

[11]. Y. B. Guo and M. Salahshoor, "Surface integrity of magnesium-calcium implants processed by synergistic dry cutting-finish burnishing, Elsevier", Procedia Engineering, 2011, 19, 288 - 293.

[12]. Birol akyuz et al., "Machinability of magnesium and its alloys", tojsat, July 2011, Volume 1, Issue 3.

[13]. Thomas Friemuth and J. Winkler, "Machining of magnesium workpieces", Advanced engineering materials, 1999, 1, no. 3-4

[14]. Birol akyuz et al., "Machinability of magnesium and its alloys", tojsat, July 2011, Volume 1, Issue 3.

[15]. S. S. Nene et al., "Microstructure refinement and its effect on specific strength and bio-corrosion resistance in ultralight $\mathrm{Mg}-4 \mathrm{Li}-1 \mathrm{Ca}$ (LC41) alloy by hot rolling", Journal of Alloys and Compounds, 2014, 615, 501-506

[16]. J. C. Outeiro et al., "Process Mechanics and Surface Integrity Induced by Dry and Cryogenic Machining of AZ31B-O Magnesium Alloy”, Procedia CIRP, 2013, 8, 487 - 492. 